\title{
BMJ Open Real-world effectiveness of app-based treatment for urinary incontinence: a cohort study
}

\author{
Pontus Rygh (D) , Ina Asklund, Eva Samuelsson
}

To cite: Rygh P, Asklund I, Samuelsson E. Realworld effectiveness of app-based treatment for urinary incontinence: a cohort study. BMJ Open 2021;11:e040819. doi:10.1136/ bmjopen-2020-040819

- Prepublication history for this paper is available online. To view these files, please visit the journal online (http://dx.doi. org/10.1136/bmjopen-2020040819).

Received 22 May 2020 Revised 19 November 2020 Accepted 03 December 2020

Check for updates

(C) Author(s) (or their employer(s)) 2021. Re-use permitted under CC BY-NC. No commercial re-use. See rights and permissions. Published by BMJ.

Department of Public Health and Clinical Medicine, Umeå University Faculty of Medicine, Umea, Sweden

Correspondence to

Pontus Rygh;

pontusrygh@gmail.com

\begin{abstract}
Objectives The efficacy of app-based treatment for stress urinary incontinence (SUI) has been demonstrated in a randomised controlled trial (RCT). In this study, we investigate the user characteristics and the effectiveness of the same app when freely available, and compare these results with the RCT.

Design Prospective cohort study.

Participants During a 17-month period, 24602 nonpregnant, non-postpartum women older than 18 years downloaded the app and responded anonymously to a questionnaire. Of these, $2672(11 \%)$ responded to the 3-month follow-up.
\end{abstract}

Intervention Three months' use of the app Tät, containing information, a pelvic floor muscle training programme and lifestyle advice.

Main outcome measures Change in symptom severity (International Consultation on Incontinence QuestionnaireUrinary Incontinence Short Form (ICIQ-UI SF)) and subjective improvement (Patient Global Impression of Improvement (PGI-I)).

Results Of the respondents, $88 \%$ lived in Sweden and $75 \%$ (18 384/24 602) were incontinent with a mean age of 45.5 (SD 14.1) years. The UI types, based on symptoms, were SUI (53\%), urgency UI (12\%), mixed UI (31\%) and undefined (4\%). The mean ICIQ-UI SF score was 8.2 (SD 4.0) at baseline. The mean ICIQ-UI SF score reduction at follow-up was 1.31 (95\% Cl: 1.19 to 1.44) with a larger reduction in those with more severe incontinence at baseline (severe/very severe 3.23 (95\% Cl: 2.85 to 3.61), moderate 1.41 (95\% Cl: 1.24 to 1.59) and slight 0.24 (95\% Cl 0.06 to 0.42$)$. When the results were weighted to match the distribution of severity in the RCT, the ICIQ-UI SF score reduction was 2.2 compared with 3.9 in the RCT. Regarding PGI-I, 65\% experienced improvement compared with $92 \%$ in the RCT.

Conclusions The app Tät was effective for selfmanagement of $\mathrm{Ul}$ even in the real world. Although the reduction in incontinence symptoms was less than in the RCT, two-thirds of the users improved. App-based treatment reaches many women without requiring resources from ordinary healthcare services.

\section{INTRODUCTION}

Urinary incontinence (UI) is common in women, and most studies show that $25 \%-45 \%$ are affected. ${ }^{1}$ UI can be divided into stress, urgency and mixed incontinence, with stress

\section{Strengths and limitations of this study}

The design of the study allows a comparison of the effect of an app intervention between participants in a randomised controlled trial and a real-world population.

- The app was developed based on research, clinical experience and user opinions, and it was thoroughly tested in several studies before release.

- Both the International Consultation on Incontinence Questionnaire-Urinary Incontinence Short Form and Patient Global Impression of Improvement are validated and recommended questionnaires for patientreported outcomes.

- Users are anonymous, which limits the ability to verify the data.

- A large proportion of the users did not respond to the follow-up.

urinary incontinence (SUI) being leakage when coughing, sneezing or exercising, urgency urinary incontinence (UUI) being an involuntary loss of urine associated with urgency, and mixed urinary incontinence (MUI) being a combination of SUI and UUI. ${ }^{2}$ The most prevalent subtype is SUI, which affects half of all incontinent women. ${ }^{34}$

UI can have a significant impact on quality of life ${ }^{5}$ but only about one-third of those affected seek care. ${ }^{67}$ Reasons for not seeking help include embarrassment when talking with a physician about the problem or considering it to be a normal part of ageing. ${ }^{8}$ Health professionals may also lack knowledge and understanding of UI. ${ }^{9}$

The recommended first-line treatment for UI is conservative management with pelvic floor muscle training (PFMT) and lifestyle interventions. ${ }^{10}$ A Cochrane review from 2018 found that PFMT cures or improves symptoms in $74 \%$ of women with SUI and also has an effect on other types of UI. ${ }^{11}$

Instructions for PFMT can be provided via the internet or within a mobile app. ${ }^{12} 13$ E-Health solutions lower the barrier to seeking treatment ${ }^{14}$ and are a cost-effective way of 
providing treatment for UI. ${ }^{15} 16$ There are many mobile apps for PFMT available, but few of them are supported by literature or have been developed by professionals. ${ }^{17}$ The app Tät has been evaluated in a randomised controlled trial (RCT) in which women in the app group improved significantly in terms of clinical symptoms, quality of life and the number of leakages after 3 months of treatment, compared with a control group. ${ }^{13}$ The app was also effective regarding the long-term incontinence symptoms and quality of life. ${ }^{18}$

Although RCTs are considered the gold standard for the evaluation of healthcare outcomes, proven interventions may not give the same results in the real world due to the selected populations and strictly controlled conditions that often exist in RCTs. ${ }^{19}$ Also, there are specific difficulties when implementing mobile app interventions, such as the varying levels of familiarity with mobile technology in the target populations, the risk of technical problems and the technologies used becoming outdated. ${ }^{20}$ For these reasons, it is important to study the effect of e-Health interventions in real-world settings.

In this study, we wanted to analyse user characteristics and change in symptoms in an unselected group of women (non-pregnant and non-postpartum) that had downloaded the freely available Tät app, and compare these results with data from the RCT. ${ }^{13}$

\section{MATERIALS AND METHODS}

This study was based on data from those who responded anonymously to a questionnaire when downloading the Tät app. Before the users of the app could answer the questionnaires, they had to provide their consent by reading a short text and ticking a box to confirm that they were aware that their answers would be sent anonymously to our research database and that results from previous research on the app were based on women with SUI. The app is freely available in App Store and Google Play and during the study it was available in six languages (Swedish, English, German, Finnish, Spanish and Arabic). Baseline data were collected from questionnaires in the app from 16 January 2018 to 1 June 2019.

The app consists of a self-management programme for SUI and contains instructions for PFMT as well as lifestyle advice. There are six basic exercises and six advanced exercises with increasing difficulty and intensity, which are recommended to be performed three times per day. Each exercise is illustrated with a bar that shows how fast, how much and for how long the muscles must be contracted. It also allows the user to set reminders and has a statistics function (figure 1). The first version of the app was developed for use in the RCT in 2013. An updated version with questionnaires incorporated into it was released for free in 2015. Several updates have been made to the platform, design, language and functions since then. However, the original 12-step programme for PFMT has not been changed. The app has been developed and updated within the eContinence project in

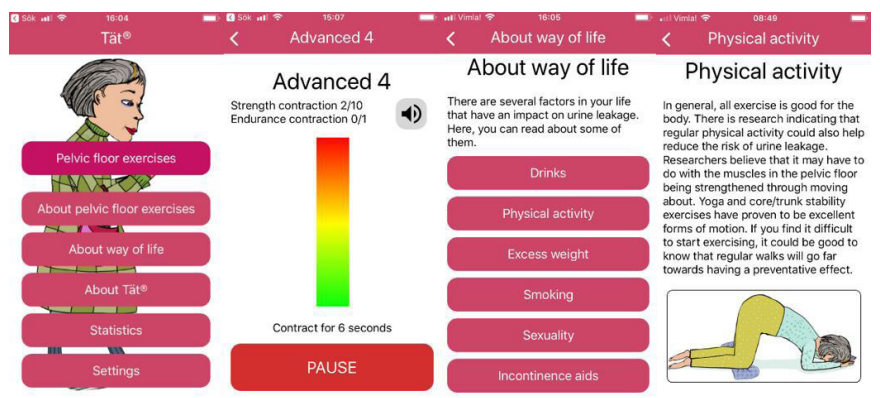

Figure 1 Screenshots from the Tät app.

collaboration with software engineers at ICT Services and System Development, Umeå University. The application is CE-marked as a medical device class 1, according to European Union regulation MDR 2017/745.

The approximate number of downloads during the period studied (16 January 2018-1 June 2019) was calculated using data from App Store and Google Play available to the administrator. App Store only collects data on installations from people who have agreed to share their diagnostics and usage information with app developers, on average $20 \%$ during the study. The number of downloads from App Store was therefore divided by 0.2 to get the approximate total number. Data regarding the exact number of downloads per month from Google Play were available from the Google Play service, we included half of the number of downloads for January 2018.

\section{Questionnaires}

On download, the user was asked to complete a baseline questionnaire with questions about demographics and symptoms of UI. The questions relating to incontinence included the validated score International Consultation on Incontinence Questionnaire-Urinary Incontinence Short Form (ICIQ-UI SF), which has a score range of 0-21 with 21 being the most severe. It consists of three scored questions on the frequency of urinary incontinence, the amount of leakage and the overall impact of urinary incontinence on everyday life. The ICIQ-UI SF also contains a non-scored self-diagnostic question. ${ }^{21}$

After 3 months a follow-up questionnaire appeared, including the ICIQ-UI SF as well as the validated Patient Global Impression of Improvement (PGI-I) question, which has a $7^{\circ}$ scale from 'very much worse' to 'very much better' ${ }^{22}$ There were also questions about how often the app had been used, how often the user had performed PFMT over the past 4 weeks, and if they had become pregnant or had given birth within the last 3 months.

Answering these questionnaires was voluntary and all content in the app could be used without the users needing to respond to the questions. The answers were sent anonymously to our research database in encrypted form and were not stored in the app. Responses from the baseline questionnaire were linked to the 3-month follow-up questionnaire through a unique app ID, but the answers could not be traced back to the user. No information about name, social security number, email address, 


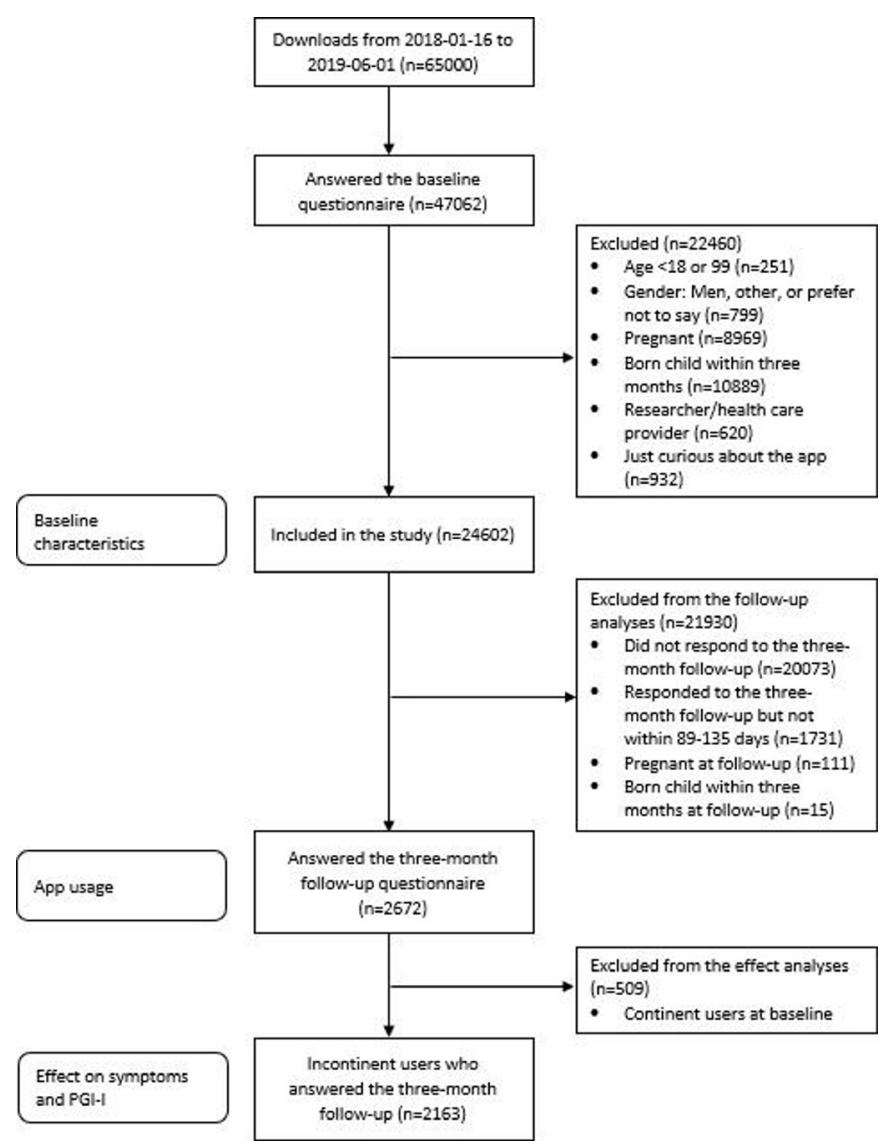

Figure 2 Flowchart of users of the freely available Tät app, at baseline and follow-up. PGI-I, Patient Global Impression of Improvement.

phone number, International Mobile Equipment Identity code or Internet Protocol address was requested or stored.

\section{Study participants}

The study included app users who identified themselves as being women over the age of 18 years who were not pregnant nor had given birth within the previous 3 months, and who stated that they downloaded the app to improve their incontinence or train preventively. Those who entered an age of 99 years were excluded as they were test users (figure 2).

Users were considered incontinent if they answered that they had both some frequency of incontinence and some amount of leakage on the ICIQ-UI SF questionnaire. Incontinent users were categorised into four groups based on their total ICIQ-UI SF score: slight (1-5), moderate (6-12), severe (13-18) and very severe. ${ }^{19-21}{ }^{23}$

Classification by type of incontinence was performed based on the self-diagnostic question in the ICIQ-UI SF, as per a previous study by Espuña-Pons et al. ${ }^{24}$ Women who indicated that they had urinary leakage when they coughed or sneezed and/or when they were physically active/exercising and did not indicate that they leaked before they reached the toilet were considered as having SUI. Those who indicated that they had urinary leakage before they reached the toilet but not when they coughed or sneezed or when they were physically active/exercising were considered as having UUI. Those who indicated that they had leakage both before they reached the toilet and when they coughed or sneezed and/or when they were physically active/exercising were considered as having MUI.

Users who responded to the 3-month follow-up questionnaire within 89-135 days were included in the analyses of app usage and change in symptoms. Change in symptoms was analysed only in users who were incontinent at baseline. Those who indicated at follow-up that they were pregnant or had given birth within the last 3 months were excluded from the follow-up analyses (figure 2).

\section{Statistical analyses}

Baseline characteristics and data regarding app usage were described as numbers and percentages or means and SD.

Differences in characteristics between those included in follow-up and those not included were analysed using the $\mathrm{X}^{2}$ test for categorical variables and the independent t-test for continuous variables.

The changes in symptoms from baseline to follow-up in incontinent users were analysed using a paired t-test and measured as change in the ICIQ-UI SF score. A t-test was conducted both for the entire group and for each incontinence severity group, as well as for each type of incontinence.

The ICIQ-UI SF score was the primary outcome in the previous RCT, the data from which were registered and reported at Clinical Trials (ID: NCT01848938). The change in the ICIQ-UI SF score in the present study was compared with the findings from the previous RCT. ${ }^{13}$ The distribution of severity in the RCT was: slight $2.4 \%$, moderate $63.4 \%$, severe $34.1 \%$, and the type of incontinence was $100 \%$ SUI. In the present study, for women with SUI we weighted the results for each severity group to match this distribution.

The user's subjective change in symptoms was measured using the PGI-I question on the follow-up questionnaire.

$P$ values of $<0.05$ were considered significant. All data were analysed using SPSS V.26.

\section{Patient and public involvement}

Users have been involved in the development of the app, and their opinions have been collected from interviews in previous studies. We have continuous email contact with users who can submit comments via a contact form on our website, econtinence.se. There was no public involvement in the development of the research questions, study design or outcome measures.

\section{RESULTS}

The Tät app was downloaded about 65000 times during the period studied and the baseline questionnaire was answered by approximately $72 \%$ (47 062) of users. Of these, 24602 users met the inclusion criteria of which 
$75 \%$ (18 384) were incontinent at baseline. Of the women included at baseline, $11 \%(2672 / 24$ 602) were included in the follow-up analysis of app usage and $12 \%$ (2163/18 384) of those who were incontinent at baseline were included in analyses of the effect on symptoms and subjective improvement (figure 2).

\section{Characteristics of the users}

The mean age of all users was 43.7 years. A total of 94 countries were represented but most of the women were from Sweden $(88.0 \%)$. Most users were well educated with $65.3 \%$ indicating 'university' as their highest level of education. In terms of the reason for downloading the app, $62.9 \%$ responded that they downloaded it to improve incontinence while $37.1 \%$ downloaded it to train preventively (table 1). Of the Swedish users, $17.7 \%$ lived in rural areas while the rest lived in towns or cities.

Incontinent users had a mean ICIQ-UI SF score of 8.2, with most users in the severity categories slight $(31.8 \%)$ or moderate $(51.6 \%)$. The distribution of types of incontinence was $53.1 \%$ with SUI, $12.1 \%$ with UUI and $30.9 \%$ with MUI, while $3.9 \%$ could not be categorised. Women with more severe incontinence had a higher mean age (slight 43.2 years, moderate 46.3 years, severe 46.8 years and very severe 52.5 years). The mean age also differed by type of incontinence (SUI 42.0 years, UUI 52.1 years and MUI 49.3 years) (table 1 ).

Those women included in the follow-up analyses had a higher prevalence of incontinence compared with those who were not included $(\mathrm{p}<0.001)$. They also had a higher level of education with a greater proportion indicating 'university' as their highest level of education $(\mathrm{p}<0.001)$. Significant differences were also seen in terms of country and language. Users who were included in the follow-up analyses had indicated Sweden $(p=0.002)$ and Swedish $(p=0.005)$ to a greater extent than those who were not included. There were no significant differences in the distribution of severity or type of incontinence between the groups (table 1).

\section{App usage}

Of the users who answered the follow-up (both incontinent and continent at baseline), $74.6 \%$ had used the app once a week or more since they downloaded it, and $51.9 \%$ had used it daily. PFMT had been performed by $90.9 \%$ of the users during the past 4 weeks and $66.6 \%$ had performed PFMT at least once a week. PFMT had been performed every day by $28.9 \%$ of the users (table 2 ).

\section{Change in incontinence symptoms}

Incontinent users improved in terms of the ICIQ-UI SF score reduction after using the app for 3 months. The mean reduction for the entire group was 1.31 (95\% CI: 1.19 to $1.44, \mathrm{p}<0.001)$. More severe incontinence at baseline was related to a greater ICIQ-UI SF score reduction, (slight, 0.24 (95\% CI: 0.06 to $0.42, \mathrm{p}=0.010$ ), moderate 1.41 (95\% CI: 1.24 to $1.59, \mathrm{p}<0.001$ ), severe and very severe 3.23 (95\% CI: 2.85 to $3.61, \mathrm{p}<0.001))$. For the different types of incontinence, the score reduction was similar to that of the entire group (SUI 1.28 (95\% CI: 1.11 to $1.45, \mathrm{p}<0.001$ ), UUI 1.33 (95\% CI: 0.95 to 1.71 , $\mathrm{p}<0.001)$ and MUI 1.34 (95\% CI: 1.09 to $1.58, \mathrm{p}<0.001)$ ) (table 3). When the results of the present study were weighted to match the distribution of type and severity of incontinence in the RCT, the ICIQ-UI SF score reduction was 2.2. According to our definition of incontinence, 13\% (282/2163) were no longer incontinent at follow-up.

Answers to the PGI-I question at follow-up showed that $65.2 \%$ experienced improvement in symptoms and $25.9 \%$ experienced their symptoms to be much better or very much better after using the app for 3 months. The proportion of those who experienced an improvement in the different groups of severity was quite similar (slight: $61.1 \%$, moderate: $68.8 \%$, severe and very severe: $62.0 \%$ ) (figure 3). No major differences in improvement of the PGI-I were seen in the different types of incontinence (SUI: $65.0 \%$, UUI: $66.2 \%$, MUI: $66.3 \%$ ).

\section{DISCUSSION}

A large number of women used the Tät app, which was previously evaluated in an RCT in women with SUI. In the real world, the app was used also for the prevention of UI and other types of UI and the severity of incontinence was lower than in the RCT. Of those who were incontinent at baseline and still used the app after 3 months, approximately two-thirds had improved. Compared with the RCT, the reduction in the ICIQ-UI SF score was lower and the users performed PFMT and used the app less. The more severe the incontinence at baseline, the greater the reduction in the ICIQ-UI SF score.

The app was developed based on research, clinical experience and user opinions. It was thoroughly tested in several studies before release and there were no technical problems during the study.

There were a large number of participants with a broad spectrum of severity in this study. The ICIQ-UI SF score and PGI-I question used in the questionnaires are validated and recommended for patient-reported outcomes which increase reliability and enable comparison with other studies.

The users were anonymous which can reduce the reliability of the responses. On the other hand, answering the questionnaire was voluntary, which probably means that those who chose to answer the questionnaire were more likely to take the time to provide reliable answers.

There was no control group in this study but the use of the app was compared with a control group in the previous RCT before it was freely released for use. ${ }^{13}$

As expected in this type of study where we did not have any contact with the participants, there was a large number who did not respond to the follow-up, $18 \%$ responded and $11 \%$ were included in the analyses. Similar response rates have been seen in studies of internet and app-based interventions for depression and anxiety in which $0.5 \%-$ $28.6 \%$ completed or used the programmes for 6 weeks 
Table 1 Characteristics of users who responded to the baseline questionnaire

\begin{tabular}{|c|c|c|c|c|}
\hline Demographics & $\begin{array}{l}\text { All users } \\
(n=24602)\end{array}$ & $\begin{array}{l}\text { Included in } \\
\text { follow-up* } \\
\text { ( } n=2672)\end{array}$ & $\begin{array}{l}\text { Not included in } \\
\text { follow-up } \\
(n=21930)\end{array}$ & $\begin{array}{l}\text { Difference } \\
\text { between } \\
\text { groupst, } p \text { value }\end{array}$ \\
\hline Mean age, years (SD) & $43.7(14.4)$ & 44.4 (13.5) & $43.6(14.5)$ & 0.002 \\
\hline Language, n (\%) & & & & 0.005 \\
\hline Swedish & $22244(90.4)$ & $2468(92.4)$ & $19776(90.2)$ & \\
\hline English & $1346(5.5)$ & $126(4.7)$ & $1220(5.6)$ & \\
\hline German & $615(2.5)$ & $50(1.9)$ & $565(2.6)$ & \\
\hline Spanish & $177(0.7)$ & $13(0.5)$ & $164(0.7)$ & \\
\hline Finnish & $102(0.4)$ & $11(0.4)$ & $91(0.4)$ & \\
\hline Arabic & $26(0.1)$ & $0(0)$ & $26(0.1)$ & \\
\hline Undefined & $92(0.4)$ & $4(0.1)$ & $88(0.4)$ & \\
\hline Country, n (\%) & & & & 0.002 \\
\hline Sweden & $21658(88)$ & $2402(89.9)$ & $19256(87.8)$ & \\
\hline Other & $2940(12)$ & $270(10.1)$ & $2670(12.2)$ & \\
\hline Undefined & $4(0)$ & $0(0)$ & $4(0)$ & \\
\hline Reason for downloading the app, $n(\%)$ & & & & $<0.001$ \\
\hline To improve incontinence & $15471(62.9)$ & $1817(68.0)$ & $13654(62.3)$ & \\
\hline To train preventively & $9131(37.1)$ & $855(32.0)$ & $8276(37.7)$ & \\
\hline Highest level of education, $\mathrm{n}(\%)$ & & & & $<0.001$ \\
\hline 6 years of school or less & $382(1.6)$ & $28(1.0)$ & $354(1.6)$ & \\
\hline $7-9$ years of school & 958 (3.9) & $48(1.8)$ & $910(4.1)$ & \\
\hline $10-12$ years of school & $7194(29.2)$ & $586(21.9)$ & $6608(30.1)$ & \\
\hline University & $16068(65.3)$ & $2010(75.2)$ & $14058(64.1)$ & \\
\hline Place of residence, $\mathrm{n}(\%)$ & & & & NS \\
\hline Rural area & $4366(17.7)$ & $457(17.1)$ & $3909(17.8)$ & \\
\hline Place/town $<50000$ people & $6721(27.3)$ & $685(25.6)$ & $6036(27.5)$ & \\
\hline Town/city 50 000-1 million people & $9137(37.1)$ & 1049 (39.3) & $8088(36.9)$ & \\
\hline Major city $>1$ million people & $4378(17.8)$ & $481(18.0)$ & $3897(17.8)$ & \\
\hline Incontinent, $\mathrm{n}(\%)$ & $18384(74.7)$ & $2163(81.0)$ & $16221(74.0)$ & $<0.001$ \\
\hline Characteristics of incontinent users & $\mathrm{n}=18384$ & $n=2163$ & $n=16221$ & \\
\hline Mean age, years (SD) & $45.5(14.1)$ & $45.6(13.3)$ & $45.5(14.2)$ & NS \\
\hline Overall score ICIQ-UI SF, mean (SD) & $8.2(4.0)$ & $8.1(3.9)$ & $8.2(4.0)$ & NS \\
\hline Symptom severity, n (\%) & & & & NS \\
\hline Slight & $5842(31.8)$ & $689(31.9)$ & $5153(31.8)$ & \\
\hline Moderate & $9479(51.6)$ & $1145(52.9)$ & $8334(51.4)$ & \\
\hline Severe & $2872(15.6)$ & $308(14.2)$ & $2564(15.8)$ & \\
\hline Very severe & $191(1.0)$ & $21(1.0)$ & $170(1.0)$ & \\
\hline Type of incontinence, $\mathrm{n}(\%)$ & & & & NS \\
\hline Stress incontinence & $9759(53.1)$ & $1196(55.3)$ & $8563(52.8)$ & \\
\hline Urgency incontinence & $2224(12.1)$ & $263(12.2)$ & $1961(12.1)$ & \\
\hline Mixed incontinence & $5684(30.9)$ & $632(29.2)$ & $5052(31.1)$ & \\
\hline Other & $717(3.9)$ & $72(3.3)$ & $645(4.0)$ & \\
\hline \multicolumn{5}{|c|}{ Mean age in each severity category, years (SD) } \\
\hline Slight & $43.2(14.0)$ & $43.5(13.0)$ & $43.2(14.1)$ & NS \\
\hline Moderate & $46.3(14.0)$ & $46.2(13.4)$ & $46.3(14.1)$ & NS \\
\hline
\end{tabular}

Continued 
Table 1 Continued

\begin{tabular}{|c|c|c|c|c|}
\hline Demographics & $\begin{array}{l}\text { All users } \\
(n=24602)\end{array}$ & $\begin{array}{l}\text { Included in } \\
\text { follow-up* } \\
(n=2672)\end{array}$ & $\begin{array}{l}\text { Not included in } \\
\text { follow-up } \\
(n=21930)\end{array}$ & $\begin{array}{l}\text { Difference } \\
\text { between } \\
\text { groupst, p value }\end{array}$ \\
\hline Severe & $46.8(13.9)$ & $47.6(13.2)$ & $46.7(14.0)$ & NS \\
\hline Very severe & $52.5(15.4)$ & $55.0(13.3)$ & $52.1(15.6)$ & NS \\
\hline \multicolumn{5}{|c|}{ Mean age in each type of incontinence, years (SD) } \\
\hline Mixed incontinence & $49.3(14.5)$ & $49.5(13.9)$ & $49.2(14.6)$ & NS \\
\hline Other & $42.2(15.8)$ & $42.9(14.8)$ & $42.2(15.9)$ & NS \\
\hline
\end{tabular}

${ }^{*}$ Responded to the follow-up questionnaire within 89-135 days. Not pregnant or no child born within previous 3 months. †Differences in characteristics of users included in analyses at follow-up compared with those who were not included, t-test for continuous variables and $\mathrm{X}^{2}$ test for categorical variables.

ICIQ-UI SF, International Consultation on Incontinence Questionnaire-Urinary Incontinence Short Form; NS, not significant.

or more. ${ }^{25}$ Previous studies have found that barriers to adhering to a PFMT programme include difficulties remembering to do the exercises, difficulties finding the time and boredom when doing the exercises. ${ }^{26}{ }^{27}$ In this study, there were also other possible explanations for the low response rate, such as users downloading the app due to curiosity but without the intention to use it, or users that learnt to perform PFMT and continued without using the app. It is possible that those who experienced improvement were more likely to use the app for 3 months and respond to the follow-up. Incontinent users responded to a greater extent, which indicates that they were more motivated than users who train preventively.

Although the app has been designed and evaluated solely for SUI, PFMT is recommended as first-line treatment for all types of incontinence, ${ }^{1}$ and many women with UUI and MUI used the app. The distribution of incontinence types across the app users aligned well with the distribution in a normal population. ${ }^{3}{ }^{4}$ This study confirms previous knowledge that older women tend to have more severe incontinence. ${ }^{3}$ The fact that the mean age differs depending on the type of incontinence is also consistent with what has been shown previously, where women with SUI have a lower mean age, while the prevalence of UUI and MUI increases with increasing age. ${ }^{4}$ PFMT has been shown to be effective primarily in SUI, ${ }^{11}$ but in this study, we found significant effects on all types of incontinence with no major differences in the ICIQ-UI $\mathrm{SF}$ score reduction or subjective improvement between different types of incontinence. However, using the selfdiagnostic question in the ICIQ-UI SF is not a validated method for determining the type of incontinence and the real distribution may have been different.

Among the app users, $65 \%$ had university education compared with the general Swedish population in which about $30 \%$ of women have university as their highest level

Table 2 App usage. Users who responded to the 3-month follow-up within 89-135 days

\begin{tabular}{|c|c|c|c|}
\hline & All users $(n=2672)$ & Incontinent users* $(n=2163)$ & Continent users ${ }^{\star}(n=509)$ \\
\hline Never & $244(9.1)$ & $190(8.8)$ & $54(10.6)$ \\
\hline 1-6 times per week & $1008(37.7)$ & $825(38.1)$ & $183(36.0)$ \\
\hline Daily & $624(23.4)$ & $516(23.9)$ & $108(21.2)$ \\
\hline \multicolumn{4}{|c|}{ How often have you used the app since you downloaded it 3 months ago? n (\%) } \\
\hline Not at all & $295(11.0)$ & $234(10.8)$ & $61(12.0)$ \\
\hline About once a month & $383(14.3)$ & $304(14.1)$ & 79 (15.5) \\
\hline About once a week & $607(22.7)$ & $485(22.4)$ & $122(24.0)$ \\
\hline
\end{tabular}

${ }^{*}$ At baseline.

PFMT, pelvic floor muscle training. 
Table 3 ICIQ-UI SF score reduction after 3 months' treatment; incontinent users who responded to the 3-month follow-up

\begin{tabular}{|c|c|c|c|c|}
\hline & $\begin{array}{l}\text { Score at baseline, } \\
\text { mean (SD) }\end{array}$ & $\begin{array}{l}\text { Score at 3-month } \\
\text { follow-up, mean (SD) }\end{array}$ & $\begin{array}{l}\text { Difference } \\
(95 \% \mathrm{Cl})\end{array}$ & P value* \\
\hline All incontinent users $(n=2163)$ & $8.11(3.87)$ & $6.80(3.97)$ & 1.31 (1.19 to 1.44$)$ & $<0.001$ \\
\hline \multicolumn{5}{|l|}{ Symptom severity } \\
\hline Slight $(n=689)$ & $4.18(0.74)$ & $3.94(2.54)$ & 0.24 (0.06 to 0.42$)$ & 0.010 \\
\hline Moderate $(n=1145)$ & $8.50(1.97)$ & $7.09(3.10)$ & 1.41 (1.24 to 1.59$)$ & $<0.001$ \\
\hline Severe/very severe $(n=329)$ & $14.98(1.93)$ & $11.76(3.80)$ & 3.23 (2.85 to 3.61$)$ & $<0.001$ \\
\hline \multicolumn{5}{|l|}{ Type of incontinence } \\
\hline Stress incontinence $(n=1196)$ & $7.66(3.70)$ & $6.38(3.78)$ & 1.28 (1.11 to 1.45$)$ & $<0.001$ \\
\hline Urgency incontinence $(n=263)$ & $7.59(3.88)$ & $6.26(4.14)$ & $1.33(0.95$ to 1.71$)$ & $<0.001$ \\
\hline Mixed incontinence $(n=632)$ & $9.20(3.96)$ & $7.86(4.02)$ & 1.34 (1.09 to 1.58$)$ & $<0.001$ \\
\hline Other $(n=72)$ & $7.89(4.01)$ & $6.26(4.14)$ & 1.63 (0.76 to 2.50$)$ & $<0.001$ \\
\hline
\end{tabular}

${ }^{*}$ Analysed with paired t-test.

ICIQ-UI SF, International Consultation on Incontinence Questionnaire-Urinary Incontinence Short Form.

of education. ${ }^{28}$ It is known that highly educated people use health apps more. ${ }^{29}$

Women in this study had milder incontinence than participants in the $\mathrm{RCT}^{13}$ and all types of incontinence were represented, unlike the RCT in which all women had SUI. When the app results were weighted to match the type of incontinence and severity in the RCT, app users had a mean reduction in the ICIQ-UI SF score of 2.2 , this compares with a mean reduction of 3.9 in the RCT. The women in the RCT performed PFMT more often than the women in this study, $41 \%$ had performed it daily in the RCT while $29 \%$ performed PFMT every day in this study. It is likely that participants in the RCT were also more conscious of the fact that they participated in a study and this factor may have caused them to give it more effort. The mean age of incontinent users was quite similar in both studies (45.5 in this study and 44.8 in the RCT), but there was a greater spread of ages in users of the freely available app with an SD of 14.1 compared with an SD of 9.7 in the RCT participants. In the RCT $92 \%$ of women experienced improvement compared with $65 \%$ in this study. According to the Cochrane review from 2018,

a little better, much better or very much better $=$ Much better or very much better

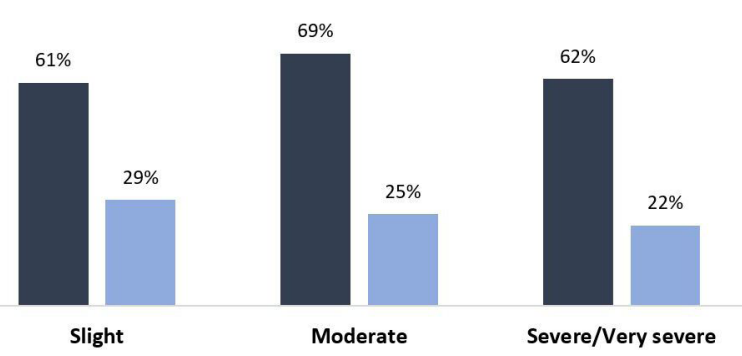

Figure 3 Patient Global Impression of Improvement: How is your urinary leakage now compared with before downloading the app? Users with slight, moderate, severe or very severe incontinence at baseline.
$67 \%$ of women with any type of incontinence reported cure or improvement with PFMT. ${ }^{11}$

The ICIQ-UI SF score reduction differed depending on the severity of incontinence at baseline, with more severe incontinence being associated with a greater ICIQ-UI SF score reduction. However, the subjective experience of improvement according to the PGI-I was quite similar between the groups. This indicates that the level of the possible reduction in the ICIQ-UI SF score is highly dependent on the pretreatment score which must be taken into account when comparing studies or interventions. The minimal clinically important difference for the ICIQ-UI $\mathrm{SF}$ was found to be 2.5 in a previous study of a PFMTbased intervention. This was established by using the mean ICIQ-UI SF score reduction of those who answered 'a little better' on the PGI-I. ${ }^{30}$ However, this group had more severe incontinence with a mean pretreatment ICIQ-UI SF score of 10.2. In our study, a large proportion of the app users had slight incontinence with a very small reduction in their ICIQ-UI SF (0.24). The lowest level of frequency of leakage in the ICIQ-UI SF is 'about once a week or less often' which makes the ICIQ-UI SF a poor measure of the effect in this group. Since $61.1 \%$ of the users with slight incontinence answered that they experienced improvement on the PGI-I question, it is likely that they also had reduced symptoms even if this is not shown in the ICIQ-UI SF score. To our knowledge, there is no other comparable study, and the best estimate of clinically relevant improvement in the population of this study is probably that $65 \%$ reported on the PGI-I that they experienced improvement.

\section{CONCLUSION}

App-based self-management of UI is an effective first-line treatment even in the real world and the symptoms of two-thirds of the users improve. However, the improvement in the ICIQ-UI SF score reduction, as well as the 
percentage that experienced subjective improvement, is lower in the real world than in the RCT. Larger reductions in symptom scores are expected the more severe the incontinence is at baseline. App-based treatment is easily accessible and can be used for women who want to manage their symptoms on their own, and also as a complement to other actions within regular healthcare.

Acknowledgements We thank all the participating women for taking the time to fill in the questionnaires in the app. We also want to acknowledge statistician Lars Söderström for his valuable input and the software engineers at ICT Services and System Development, Umeå University who helped to develop the app.

Contributors PR performed the statistical analyses, interpreted results and wrote the initial draft of the manuscript. IA supervised the statistical analyses, interpreted the results, and reviewed and revised the manuscript. ES designed, supervised and led the study, interpreted the results, and reviewed and revised the manuscript. All authors approved the final version of the manuscript.

Funding The study was funded by grants from the Kamprad family foundation for entrepreneurship, research and charity (Ref 20170202), Region Jämtland Härjedalen (Ref JLL-933083) and Visare Norr, Northern County Councils (Ref 931113).

Competing interests The name Tät and the logo Tät.nu are registered as trademarks by The Swedish Patent and Registration office for ES at Umeå University.

Patient and public involvement Patients and/or the public were not involved in the design, or conduct, or reporting, or dissemination plans of this research.

Patient consent for publication Not required.

Ethics approval The study was approved by the Regional Ethical Review Board, Umeå (2014-389-32M, 2016-80-32M and 2017-405-32M added to 2012-325-31M).

Provenance and peer review Not commissioned; externally peer reviewed.

Data availability statement Data are available upon reasonable request. The data that support the findings of this study are available from the corresponding author upon reasonable request.

Open access This is an open access article distributed in accordance with the Creative Commons Attribution Non Commercial (CC BY-NC 4.0) license, which permits others to distribute, remix, adapt, build upon this work non-commercially, and license their derivative works on different terms, provided the original work is properly cited, appropriate credit is given, any changes made indicated, and the use is non-commercial. See: http://creativecommons.org/licenses/by-nc/4.0/.

\section{ORCID iD}

Pontus Rygh http://orcid.org/0000-0003-4723-6152

\section{REFERENCES}

1 Abrams P, Milsom I, Altman D, et al. Epidemiology of urinary incontinence (UI) and other lower urinary tract symptoms (LUTS), pelvic organ prolapse (POP) and anal incontinence (AI). In: Abrams P, Cardozo L, Wagg A, et al, eds. Incontinence . 6th edition. Bristol UK: ICI-ICS. International Continence Society, 2017. ISBN: 9780956960733.

2 Haylen BT, de Ridder D, Freeman RM, et al. An International Urogynecological Association (IUGA)/International Continence Society (ICS) joint report on the terminology for female pelvic floor dysfunction. Neurourol Urodyn 2010;29:4-20.

3 Hannestad YS, Rortveit G, Sandvik H, et al. A community-based epidemiological survey of female urinary incontinence: the Norwegian EPINCONT study. J Clin Epidemiol 2000;53:1150-7.

4 Hunskaar S, Lose G, Sykes D, et al. The prevalence of urinary incontinence in women in four European countries. BJU Int 2004;93:324-30.

5 Gasquet I, Tcherny-Lessenot S, Gaudebout P, et al. Influence of the severity of stress urinary incontinence on quality of life, health care seeking, and treatment: a national cross-sectional survey. Eur Urol 2006:50:818-25.

6 O'Donnell M, Lose G, Sykes D, et al. Help-seeking behaviour and associated factors among women with urinary incontinence in France, Germany, Spain and the United Kingdom. Eur Urol 2005;47:385-92. discussion 392.

7 Hannestad YS, Rortveit G, Hunskaar S. Help-Seeking and associated factors in female urinary incontinence. The Norwegian EPINCONT study. epidemiology of incontinence in the County of NordTrøndelag. Scand J Prim Health Care 2002;20:102-7.

8 Kinchen KS, Burgio K, Diokno AC, et al. Factors associated with women's decisions to seek treatment for urinary incontinence. $J$ Womens Health 2003;12:687-98.

9 Orrell A, McKee K, Dahlberg L, et al. Improving continence services for older people from the service-providers' perspective: a qualitative interview study. BMJ Open 2013;3. doi:10.1136/ bmjopen-2013-002926. [Epub ahead of print: 30 Jul 2013].

10 Lukacz ES, Santiago-Lastra Y, Albo ME, et al. Urinary incontinence in women: a review. JAMA 2017;318:1592-604.

11 Dumoulin C, Hay-Smith EJC, Mac Habée-Séguin G. Pelvic floor muscle training versus no treatment, or inactive control treatments, for urinary incontinence in women. Cochrane Database Syst Rev 2014:CD005654.

12 Sjöström M, Umefjord G, Stenlund H, et al. Internet-based treatment of stress urinary incontinence: a randomised controlled study with focus on pelvic floor muscle training. BJU Int 2013;112:362-72.

13 Asklund I, Nyström E, Sjöström M, et al. Mobile app for treatment of stress urinary incontinence: a randomized controlled trial. Neurourol Urodyn 2017;36:1369-76.

14 Verhoeks C, Teunissen D, van der Stelt-Steenbergen A, et al. Women's expectations and experiences regarding e-health treatment: a systematic review. Health Informatics J 2019;25:771-87.

15 Sjöström M, Umefjord G, Lindholm L, et al. Cost-effectiveness of an Internet-based treatment program for stress urinary incontinence. Neurourol Urodyn 2015;34:244-50.

16 Sjöström M, Lindholm L, Samuelsson E. Mobile app for treatment of stress urinary incontinence: a cost-effectiveness analysis. $J$ Med Internet Res 2017;19:e154.

17 Barnes KL, Dunivan G, Jaramillo-Huff A, et al. Evaluation of smartphone pelvic floor exercise applications using standardized scoring system. Female Pelvic Med Reconstr Surg 2019;25:328-35.

18 Hoffman V, Söderström L, Samuelsson E. Self-management of stress urinary incontinence via a mobile app: two-year followup of a randomized controlled trial. Acta Obstet Gynecol Scand 2017;96:1180-7.

19 Nallamothu BK, Hayward RA, Bates ER. Beyond the randomized clinical trial: the role of effectiveness studies in evaluating cardiovascular therapies. Circulation 2008;118:1294-303.

20 Ben-Zeev D, Schueller SM, Begale M, et al. Strategies for mHealth research: lessons from 3 mobile intervention studies. Adm Policy Ment Health 2015;42:157-67.

21 Avery K, Donovan J, Peters TJ, et al. ICIQ: a brief and robust measure for evaluating the symptoms and impact of urinary incontinence. Neurourol Urodyn 2004;23:322-30.

22 Yalcin I, Bump RC. Validation of two global impression questionnaires for incontinence. Am J Obstet Gynecol 2003;189:98-101.

23 Klovning A, Avery K, Sandvik H, et al. Comparison of two questionnaires for assessing the severity of urinary incontinence: the ICIQ-UI SF versus the incontinence severity index. Neurourol Urodyn 2009;28:411-5.

24 Espuña-Pons M, Dilla T, Castro D, et al. Analysis of the value of the ICIQ-UI SF questionnaire and stress test in the differential diagnosis of the type of urinary incontinence. Neurourol Urodyn 2007;26:836-41.

25 Fleming T, Bavin L, Lucassen M, et al. Beyond the trial: systematic review of real-world uptake and engagement with digital self-help interventions for depression, low mood, or anxiety. J Med Internet Res 2018;20:e199.

26 Borello-France D, Burgio KL, Goode PS, et al. Adherence to behavioral interventions for stress incontinence: rates, barriers, and predictors. Phys Ther 2013;93:757-73.

27 Venegas M, Carrasco B, Casas-Cordero R. Factors influencing long-term adherence to pelvic floor exercises in women with urinary incontinence. Neurourol Urodyn 2018;37:1120-7.

28 SCB statistical database, Befolkningens utbildning. Available: https://www.scb.se/hitta-statistik/statistik-efter-amne/utbildningoch-forskning/befolkningens-utbildning/befolkningens-utbildning/ [Accessed 26 Nov 2019].

29 Carroll JK, Moorhead A, Bond R, et al. Who uses mobile phone health Apps and does use matter? a secondary data analytics approach. J Med Internet Res 2017;19:e125.

30 Nyström E, Sjöström M, Stenlund $\mathrm{H}$, et al. ICIQ symptom and quality of life instruments measure clinically relevant improvements in women with stress urinary incontinence. Neurourol Urodyn 2015;34:747-51. 